\title{
Ultrasound-guided percutaneous peripheral nerve stimulation for analgesia following total knee arthroplasty: a prospective feasibility study
}

Brian M. Ilfeld ${ }^{1 *}$, Christopher A. Gilmore ${ }^{2,3,4}$, Stuart A. Grant ${ }^{5}$, Michael P. Bolognesi ${ }^{6}$, Daniel J. Del Gaizo ${ }^{7}$, Amorn Wongsarnpigoon ${ }^{8}$ and Joseph W. Boggs ${ }^{8}$

\begin{abstract}
Background: Peripheral nerve stimulation has been used for decades to treat chronic pain but has not been used for postoperative analgesia due to multiple limitations, beginning with invasive electrode placement. With the development of small-diameter/gauge leads enabling percutaneous insertion, ultrasound guidance for accurate introduction, and stimulators small enough to be adhered to the skin, neurostimulation may now be provided in a similar manner to continuous peripheral nerve blocks. Here, we report on the use of ultrasound-guided percutaneous peripheral nerve stimulation to treat postoperative pain.

Materials and methods: Subjects within 60 days of a total knee arthroplasty with pain insufficiently treated with oral analgesics had a 0.2-mm-diameter electrical lead (pre-loaded into a 20 gauge needle) introduced percutaneously using ultrasound guidance with the tip located approximately $0.5-1.0 \mathrm{~cm}$ from the femoral nerve (a second lead was inserted approximately $1.0-3.0 \mathrm{~cm}$ from the sciatic nerve for posterior knee pain). An external stimulator delivered current. Endpoints were assessed before and after lead insertion and the leads subsequently removed. Due to the small sample size for this pilot/feasibility study, no statistics were applied to the data.
\end{abstract}

Results: Leads were inserted in subjects $(n=5)$ 8-58 days postoperatively. Percutaneous peripheral nerve stimulation decreased pain an average of $93 \%$ at rest (from a mean of 5.0 to 0.2 on a $0-10$ numeric rating scale), with 4 of 5 subjects experiencing complete resolution of pain. During passive and active knee motion pain decreased an average of 27 and 30\%, respectively. Neither maximum passive nor active knee range-of-motion was consistently affected.

Conclusions: Ultrasound-guided percutaneous peripheral nerve stimulation may be a practical modality for the treatment of postoperative pain following orthopedic surgical procedures, and further investigation appears warranted.

Keywords: Ultrasound-guided analgesia, Peripheral nerve stimulation, Postoperative analgesia, Acute pain, Neuromodulation, Neurostimulation, Ultrasound-guided percutaneous peripheral nerve stimulation, Orthopedic surgery, Total knee arthroplasty, Total knee replacement

\footnotetext{
* Correspondence: bilfeld@ucsd.edu

Presented in part, as a scientific abstract for the Annual Meeting of the North American Neuromodulation Society in Las Vegas, Nevada, December 11-12,

2015.

Presented in part, as a scientific abstract for the Annual Meeting of the

American Society of Regional Anesthesia in New Orleans, Louisiana, April 1,

2016.

'Department of Anesthesiology, University of California San Diego, 200 West

Arbor Drive, MC 8770, San Diego, CA 92103-8770, USA

Full list of author information is available at the end of the article
} 


\section{Background}

Total knee arthroplasty often results in moderate-tosevere pain that is frequently treated with opioids, themselves correlated with unwelcome side effects such as sedation, nausea, vomiting, respiratory depression, and abuse [1]. Other analgesic techniques such as continuous peripheral nerve blocks have their own limitations as they induce quadriceps weakness and are associated with an increased risk of falling [2]; duration limitations because of the risk of infection [3]; and, for outpatients, the encumbrance of carrying the local anesthetic reservoir and portable infusion pump [4]. An alternative analgesic modality-peripheral nerve stimulation-may deliver post-surgical pain control without the limitations of currently available analgesic techniques.

Peripheral nerve stimulation was initially described to treat pain over 2,000 years ago with the use of the electrical charge generated by Torpedo Fish [5]. Many hypotheses have been proposed to explain the analgesic effects of stimulation [6], but Melzack and Wall's "gate control theory" is the most common and accepted theory [7]. In 1967, Melzack and Wall described how large-diameter myelinated afferent peripheral nerve fibers were activated by electrical current which, in turn, impeded pain signal conduction (the "gate") within the spinal cord, to the central nervous system from small-diameter pain fibers [7, 8]. Soon thereafter, Wall and Sweet hypothesized that stimulating primary afferent neurons could produce analgesia [9]. Subsequently, off-label use of commercially available stimulators was described to deliver nerve stimulation to peripheral nerves [10]. In the past 40 years, surgically implanted peripheral nerve and spinal cord stimulators have been validated and thoroughly investigated in managing chronic pain $[11,12]$.

However, using neurostimulation to treat surgically induced pain has been dramatically restricted by the invasive nature of the available electrical leads that required a surgical incision to both insert and remove the multiple electrodes oriented in close proximity to the peripheral nerve [13]. In addition, the potential for nerve damage was not insignificant, and approximately onequarter of reported implants resulted in lead migration or failure, necessitating surgical revision [10, 14-21]. Finally, fibrous capsule formation adherent to the target nerve frequently led to difficult lead removal [21]. Transcutaneous electrical nerve stimulation-involving the use of large skin electrodes-circumvents these limitations [22, 23]; but, skin pain fiber activation limits the amount of tolerated current, creating an unacceptably low "ceiling" effect [24].

To facilitate the application of peripheral nerve stimulation in treating pain resulting from surgical procedures such as total knee arthroplasty, an analgesic technique should optimally be administered without the requirement of an open surgical incision for either insertion or removal. This may be accomplished with the use of very small gauge electrical leads that allow the relatively rapid insertion via a percutaneously placed needle $[25,26]$. Using ultrasound guidance to guide the insertion needle, a lead may be consistently introduced $0.5-3.0 \mathrm{~cm}$ from a peripheral nerve utilizing the same general landmarks and approach as for perineural nerve block administration [27, 28]. Ultrasound-guided percutaneous peripheral nerve stimulation was first reported in situ by Huntoon in 2009 using an epidural neurostimulation electrode for the treatment of chronic neuropathic pain [29]. Although related methods were later described for other chronic pain conditions [30-32], it has yet to be applied to a post-surgical pain state. We now report, to our knowledge, the first use of ultrasound-guided percutaneous peripheral nerve stimulation to treat postsurgical pain.

\section{Methods}

\section{Consent to publish}

This prospective feasibility study was conducted within the ethical guidelines outlined in the Declaration of Helsinki and followed Good Clinical Practice. Approval and oversight were provided by two Institutional Review Boards (Western IRB, Puyallup, WA; and Duke University Health System IRB, Durham, NC). An Investigational Device Exemption was granted for the use of these investigational devices by the US Food and Drug Administration (FDA), and written, informed consent was obtained from all subjects. The protocol was not registered as this was not a randomized, controlled trial.

We enrolled a convenience sample of adult subjects (21 years and older) with surgically related joint pain $(\geq 3$




on an 11-point numerical rating scale of the Brief Pain Inventory Short Form, Question 3: "Pain at its worst in the last $24 \mathrm{~h}$ ") uncontrolled with oral analgesics within 60 days following primary, unilateral, total (e.g., tricompartment) knee arthroplasty. Key exclusion criteria included the presence of implanted cardiac or deep brain stimulators, ongoing infections of the affected limb or other factors that increase the risk of infection, increased risk of bleeding (e.g., bleeding disorder), confounding pain conditions unrelated to the clinical indication for the knee arthroplasty (e.g., fibromyalgia), and nerve damage to the affected limb.

\section{Materials}

The investigational stimulation system used in the present study includes components (e.g., lead, stimulator) of a stimulation system that recently received FDA 510(k) clearance for the treatment of chronic and acute pain, including post-surgical and post-traumatic pain. Electrical stimulation was delivered through a helically coiled monopolar insulated electrical lead MicroLead $^{\mathrm{Tm}}$, SPR Therapeutics, Cleveland, $\mathrm{OH}$ ), which was pre-loaded in a $12.5 \mathrm{~cm}, 20$ gauge introducer needle (Fig. 1). The lead was connected to a battery-powered electrical stimulator that was connected to the body via a surface return electrode (SPR Therapeutics, Cleveland, $\mathrm{OH}$ ). To deliver test stimulation prior to lead placement, a $7.5 \mathrm{~cm}, 25$ gauge or $12.5 \mathrm{~cm}$, 24 gauge monopolar needle electrode (Test Needle, SPR Therapeutics, Cleveland, $\mathrm{OH}$ ) was inserted. To guide placement of the lead and needle electrode, ultrasound imaging was used (M-Turbo, SonoSite, Bothell, WA; Flex Focus 400 exp, BK Medical, Peabody, MA) along with a linear array transducer (HFL38x 13-6 MHz 38 mm, SonoSite, Bothell, WA; Type 8870 18-6 MHz 60 mm, BK Medical, Peabody, MA) or curved array transducer (C60x 5-2 MHz $60 \mathrm{~mm}$ SonoSite, Bothell, WA; Type 8820e, 6-2 MHz 200 mm, BK Medical, Peabody, MA) to target femoral and sciatic nerves, respectively, within a sterile sleeve.

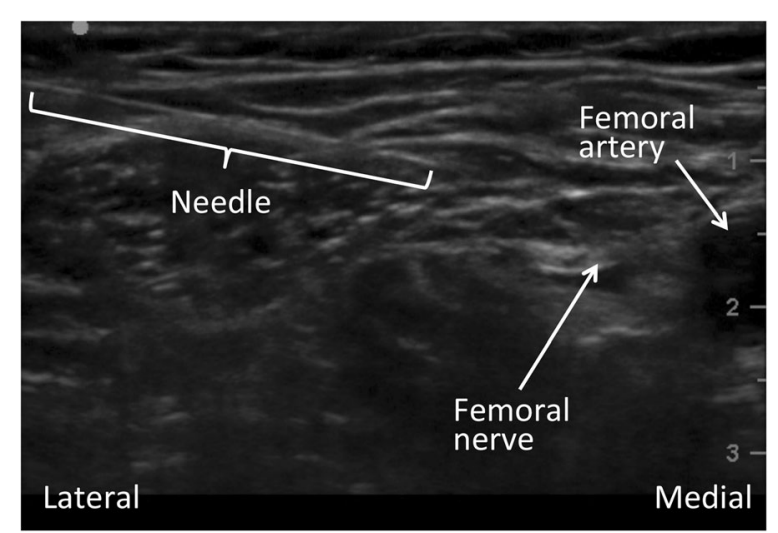

Fig. 2 Ultrasound image of a femoral lead insertion

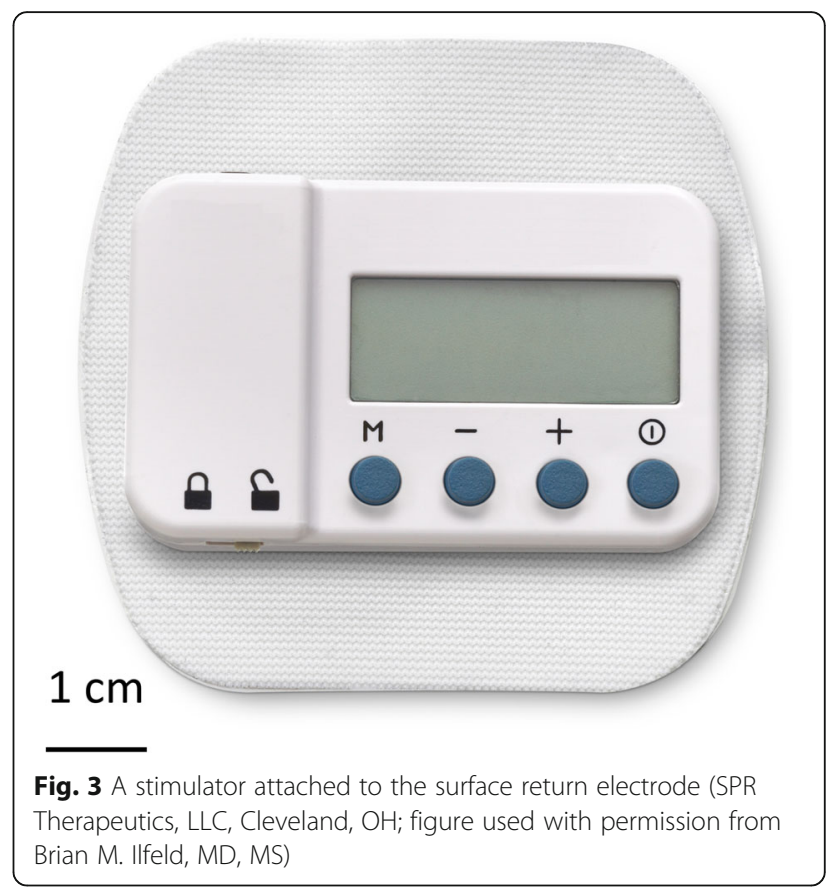

\section{Lead placement}

The anatomic lead location was determined by the origination of pain: anterior knee pain was treated with a femoral lead, and posterior knee pain received a sciatic lead. Subjects were positioned either supine or in the lateral decubitus position for femoral and sciatic insertions,

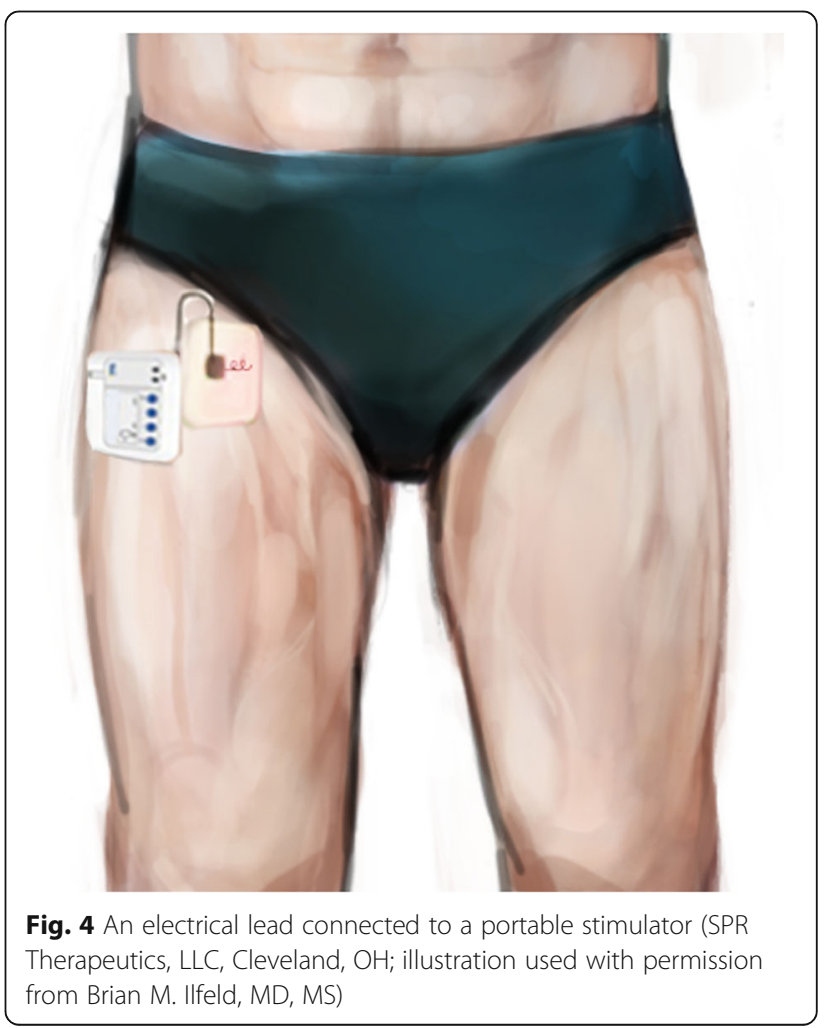


Table 1 Subject characteristics

\begin{tabular}{lllllllr}
\hline Subject & Days since surgery & Diagnosis & Fixation method & Age (years) & Sex & BMl $\left(\mathrm{kg} / \mathrm{m}^{2}\right)$ & Leg \\
\hline A & 8 & Osteoarthritis & Cement & 48 & Male & 30 & Left \\
B & 9 & Osteoarthritis & Cement & 56 & Female & 26 & Left \\
C & 13 & Osteoarthritis & Cement & 73 & Female & 36 & Left \\
D & 41 & Osteoarthritis & Unknown & 66 & Male & 34 & Left \\
E & 58 & Osteoarthritis & Unknown & 61 & Female & 51 & Left \\
Mean & 26 & & & 61 & & 35 & \\
\hline
\end{tabular}

$B M I$ body mass index

respectively. Subjects had their ipsilateral limb prepared with chlorhexidine gluconate/isopropyl alcohol solution and sterile drapes at the level of the inguinal crease or over the gluteus maximus muscle for femoral and sciatic insertions, respectively. Nerves were imaged using ultrasound in a transverse cross-sectional (short axis) view at the inguinal crease for femoral leads and between the ischial tuberosity and greater trochanter for sciatic leads (Fig. 2). A local anesthetic skin wheal was raised lateral to the transducer, and no sedation was utilized.

To deliver test stimulation prior to lead placement, the monopolar needle electrode was inserted within the ultrasound plane and positioned approximately $0.5-1.0 \mathrm{~cm}$ from the femoral and $1.0-3.0 \mathrm{~cm}$ from the sciatic nerves. The electrical stimulator was used to deliver test stimulation $(100 \mathrm{~Hz}, 15-200 \mu \mathrm{sec}, 0.2-20 \mathrm{~mA})$ to verify that comfortable sensations within the regions of pain could be induced without discomfort or evoking muscle contractions. If local cutaneous or subcutaneous discomfort was reported-indicating too superficial electrode placement-the needle electrode was advanced until resolution of the undesired sensations. If muscle contractions and/or discomfort distal to the lead insertion site were induced, the current intensity was reduced and/or the needle electrode was redirected until the contractions resolved.

Following a successful test (comfortable sensations and/ or pain relief within the regions of pain without discomfort or muscle contractions), the monopolar needle electrode was withdrawn and replaced with the lead introducer needle (Fig. 1) using the same skin entry point and ultrasound approach. The final needle tip location was in the same location as the monopolar needle electrode (i.e., approximately $0.5-3.0 \mathrm{~cm}$ from the nerve). The needle was then withdrawn over the pre-loaded helically coiled electrical lead, the lead attached to a stimulator, and the stimulator subsequently attached to a surface return electrode (Fig. 3). Comfortable sensations over the regions of pain without muscle contractions confirmed accurate lead placement.

A short portion of the lead outside the body was formed into a loop and affixed to the skin at the point of exit using an occlusive dressing (Fig. 4). For subjects with pain in the posterior aspect of the knee, a second lead was inserted between approximately $0.5-3.0 \mathrm{~cm}$ from the sciatic nerve between the greater trochanter and ischial tuberosity, using the technique described for the femoral lead. Following the measurement of the endpoints, the occlusive dressing was removed and gentle traction applied to the lead for extraction. A small sterile bandage was applied at the lead exit point.

\section{Outcome measures}

Pain "right now" was evaluated first at rest and subsequently with passive and active knee motion using a Numeric Rating Scale of $0-10$, with 0 and 10 equivalent

Table 2 Procedure-related pain and stimulation parameters

\begin{tabular}{|c|c|c|c|c|c|c|c|c|c|}
\hline \multirow{3}{*}{ Subject } & \multirow{3}{*}{ Catheter location } & \multirow{3}{*}{$\begin{array}{l}\text { Procedure-related pain } \\
\text { (NRS) }\end{array}$} & \multicolumn{7}{|c|}{ Stimulation parameters } \\
\hline & & & \multicolumn{2}{|c|}{ Minimum sensation } & \multicolumn{2}{|c|}{ Maximum tolerable } & \multicolumn{3}{|c|}{ Optimal settings } \\
\hline & & & $(\mu \mathrm{s})$ & $(m A)$ & $(\mu \mathrm{s})$ & $(m A)$ & $(\mu \mathrm{s})$ & $(m A)$ & $(\mathrm{Hz})$ \\
\hline \multirow[t]{2}{*}{$\bar{A}$} & femoral & 2 & 15 & 6 & 15 & 10 & 15 & 9 & 100 \\
\hline & sciatic & & 18 & 20 & 18 & 20 & 18 & 20 & 100 \\
\hline B & femoral & 0 & 15 & 1 & 17 & 20 & 15 & 20 & 100 \\
\hline \multirow[t]{2}{*}{ C } & femoral & 4 & 15 & 10 & 22 & 20 & 15 & 18 & 100 \\
\hline & sciatic & & 15 & 20 & 200 & 20 & 50 & 20 & 100 \\
\hline D & femoral & 2 & 15 & 5 & 26 & 20 & 19 & 20 & 100 \\
\hline $\mathrm{E}$ & femoral & 1 & 15 & 1 & 15 & 5 & 15 & 5 & 100 \\
\hline Mean & & 1.8 & 15 & 9 & 45 & 16 & 21 & 16 & 100 \\
\hline
\end{tabular}

NRS numeric rating scale $(0-10)$ 
Table 3 Pain at baseline and during percutaneous peripheral nerve stimulation with electric current

\begin{tabular}{lllll}
\hline Subject & $\begin{array}{l}\text { Days } \\
\text { since } \\
\text { surgery }\end{array}$ & \multicolumn{2}{l}{ At rest } & \% Change \\
\cline { 3 - 4 } & & \multicolumn{2}{l}{ Stimulation } & \\
\cline { 3 - 4 } & 8 & 3 & 1 & $67 \%$ \\
A & 9 & 3 & 0 & $100 \%$ \\
C & 13 & 7 & 0 & $100 \%$ \\
D & 41 & 5 & 0 & $100 \%$ \\
E & 58 & 7 & 0 & $100 \%$ \\
Mean & 26 & 5.0 & 0.2 & $93 \%$ \\
\hline
\end{tabular}

Pain evaluated using a numeric rating scale (0-10)

to no pain and the worst imaginable pain, respectively (Question 6 of the Brief Pain Inventory, Short Form). Endpoints were evaluated immediately prior to lead insertion(s) and during the delivery of current. Passive and active knee range-of-motion was measured using a standard goniometer and included the number of degrees between the maximum flexion and extension measurements.

\section{Safety}

Subjects received a telephone call 24 to $48 \mathrm{~h}$ after testing to evaluate the safety of the lead exit site. Also, subjects were instructed to contact the investigators for any device- or procedure-related adverse events after testing.

\section{Results}

Five subjects were enrolled meeting all inclusion/exclusion criteria (Table 1). Leads were inserted without difficulty in all subjects; and stimulation produced comfortable sensations in the thigh/knee areas without discomfort or muscle contractions (Table 2). Percutaneous peripheral nerve stimulation produced immediate analgesia, decreasing pain an average of $93 \%$ at rest (mean NRS from 5.0 to 0.2 ) with 4 of 5 subjects experiencing complete resolution of pain (Table 3). In addition, pain during passive and active knee motion was reduced to 27 and $30 \%$, respectively (Table 4). Neither maximum passive nor active knee range-of-motion was consistently affected (Table 5).

All leads were removed without difficulty approximately $1-2 \mathrm{~h}$ after the start of testing. There were no device-related adverse events.

\section{Discussion}

This prospective feasibility case series suggests that ultrasound-guided percutaneous peripheral nerve stimulation may be applicable to pain following total knee arthroplasty. The relatively recent convergence of five advances may now allow the wide application of this modality to treat post-surgical pain: (1) the recent propagation of ultrasound machines available to practitioners for use in regional analgesia; (2) the current pervasiveness of anesthesiologists trained in ultrasoundguided regional anesthesia; (3) an insulated electrical lead specially developed for percutaneous insertion and extended use adjacent to peripheral nerves that enables selective activation of pain-relieving fibers when inserted remote (approximately $0.5-3.0 \mathrm{~cm}$ ) from the target nerve; (4) a novel stimulator that may be adhered directly to the skin due to its small footprint and slim design; and (5) the recent FDA 510(k) clearance of this percutaneous peripheral nerve stimulation system for the treatment of chronic pain and acute pain, including post-surgical and post-traumatic pain.

The novel electrical leads used in this investigation were comprised of a small-diameter open helical coil $(0.2 \mathrm{~mm}$ wire diameter and $0.6 \mathrm{~mm}$ overall coil diameter) wound from a fluoropolymer insulated 7-strand, type 316L stainless steel wire with a single terminal anchor at the tip (Fig. 5). The lead was specifically designed to provide multiple advantages that increase the applicability of nerve stimulation to the management of post-surgical pain. Percutaneous insertion with a $20 \mathrm{~g}$ needle is possible due to the relatively small coil diameter (Fig. 1), and removal may be achieved simply with continuous traction. The helical

Table 4 Pain at baseline and during percutaneous peripheral nerve stimulation with electric current

\begin{tabular}{|c|c|c|c|c|c|c|c|}
\hline \multirow[t]{3}{*}{ Subject } & \multirow{3}{*}{$\begin{array}{l}\text { Days since } \\
\text { surgery }\end{array}$} & \multicolumn{3}{|c|}{ During passive range-of-motion } & \multicolumn{3}{|c|}{ During active range-of-motion } \\
\hline & & \multicolumn{2}{|c|}{ Stimulation } & \multirow[t]{2}{*}{ \% Change } & \multicolumn{2}{|c|}{ Stimulation } & \multirow[t]{2}{*}{ \% Change } \\
\hline & & Off & On & & Off & On & \\
\hline A & 8 & 5 & 5 & $0 \%$ & 5 & 5 & $0 \%$ \\
\hline B & 9 & 5 & 2 & $60 \%$ & 6 & 4 & $33 \%$ \\
\hline C & 13 & 7 & 5 & $29 \%$ & 6 & 4 & $33 \%$ \\
\hline D & 41 & 9 & 8 & $11 \%$ & 9 & 6 & $33 \%$ \\
\hline $\mathrm{E}$ & 58 & 6 & 3 & $50 \%$ & 6 & 4 & $33 \%$ \\
\hline Mean & 26 & 6.4 & 4.6 & $30 \%$ & 6.4 & 4.6 & $27 \%$ \\
\hline
\end{tabular}

Pain evaluated using a numeric rating scale $(0-10)$ 
Table 5 Range-of-motion at baseline and during percutaneous peripheral nerve stimulation with electric current

\begin{tabular}{|c|c|c|c|c|c|c|}
\hline \multirow[b]{3}{*}{ Subject } & \multicolumn{3}{|c|}{ Passive range-of-motion } & \multicolumn{3}{|c|}{ Active range-of-motion } \\
\hline & \multicolumn{2}{|c|}{ Stimulation } & \multirow[t]{2}{*}{ Change } & \multicolumn{2}{|c|}{ Stimulation } & \multirow[t]{2}{*}{ Change } \\
\hline & $\overline{\mathrm{Off}}$ & On & & $\overline{\text { Off }}$ & On & \\
\hline$A$ & 61 & 60 & -1 & 57 & 53 & -4 \\
\hline B & 21 & 39 & 18 & 10 & 54 & 44 \\
\hline C & 63 & 70 & 7 & 75 & 61 & -14 \\
\hline $\mathrm{D}$ & 111 & 116 & 5 & 100 & 110 & 10 \\
\hline E & 88 & 80 & -8 & 87 & 88 & 1 \\
\hline Mean & 69 & 73 & 4 & 66 & 73 & 7 \\
\hline
\end{tabular}

Active and passive knee range-of-motion was measured using a standard goniometer and included the number of degrees between the maximum flexion and extension measurements

shape theoretically decreases the incidence of fracture and migration, as well as lowering the risk of infection to less than $0.1 \%$ for up to 60 days [33]. The minimal infection risk and investigational device exemption (IDE) from the US FDA for use up to 60 days in clinical investigations raises the possibility of providing post-surgical analgesia that outlasts the pain resulting from not only total knee arthroplasty but the overwhelming majority of orthopedic procedures. It is for this reason that we included subjects who were within 60 days of surgery for the current investigation.

The single coiled monopolar lead enables a stimulation paradigm that is intended to provide pain relief while minimizing muscle contractions and discomfort from stimulation. The challenge with peripheral nerve stimulation for the treatment of pain has been to activate selectively the pain-relieving (large-diameter myelinated) fibers within a nerve trunk while avoiding activation of smaller diameter (alpha motoneurons, or types III and IV) fibers. This "selective activation" of large over small diameter fibers improves as pulse duration decreases [34] and the distance between the electrode and nerve increases [35]. Compared to conventional peripheral nerve stimulation that uses multi-electrode leads placed close to the nerve (commonly $\leq 0.2 \mathrm{~cm}$ ) and wide pulse durations $(90-500 \mu \mathrm{s})$, the stimulation paradigm in the present study utilized remote lead placement (approximately $0.5-3.0 \mathrm{~cm}$ from the nerve) and narrow pulse durations $(15-50 \mu \mathrm{s})$. Such remote lead placement is enabled by the ability of the single, coiled monopolar lead to resist migration due to its coiled structure and terminal anchor at the electrode (Fig. 6).

In addition, the positive results of the present study are unlikely to be due to peripheral nerve field stimulation, where electrodes are placed subcutaneously near the regions of pain to activate adjacent nerve fibers to generate sensations locally to relieve pain. In contrast, the present technique directly stimulated peripheral nerves proximal to the surgical wound to produce sensations and analgesia distal to the leads within the nerve distributions.

Percutaneous peripheral nerve stimulation produced immediate reductions in pain that compare favorably to existing treatments for postoperative pain. Pain at rest was completely relieved in 4 of 5 subjects (overall average relief $=93 \%$ ), and pain during passive and active flexion was decreased 27 and 30\%, respectively. Although one subject did not achieve complete relief of pain at rest with stimulation on (pain $=1$ ) compared to stimulation off (pain $=3$ ), adjustment of the lead location and/or stimulation parameters may have enabled this subject to achieve complete pain relief. With this small feasibility study, we can only speculate on the degree of pain control provided with percutaneous peripheral nerve stimulation relative to single injection and continuous peripheral nerve blocks [4]. However, it is notable that adductor canal blocks reduced pain to a similar degree following total knee arthroplasty, albeit immediately following surgery $[36,37]$.

Ultrasound-guided percutaneous peripheral nerve stimulation has several important limitations. Small lead fragments, typically less than $0.1 \mathrm{~mm}^{3}$ in volume (less than a tenth of the volume of a common skin staple) and $0.8 \mathrm{mg}$ in weight, may be retained upon withdrawal of the lead at the end of the therapy period. MRI scanning may still be performed on a patient with a retained fragment since the retained fragments are MR conditional using common scanning conditions at 1.5 Tesla [38]. Also, no lead fractures have been reported within the body during therapy and retained fragments have not produced complications when left

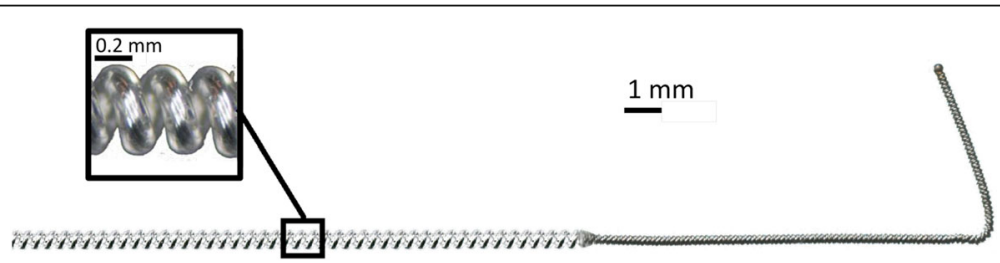

Fig. 5 A small-diameter $(0.2 \mathrm{~mm}$ ) open-coiled, helical electrical lead with an anchoring wire (MicroLead, SPR Therapeutics, LLC, Cleveland, OH; figure used with permission from Brian M. Ilfeld, MD, MS) 


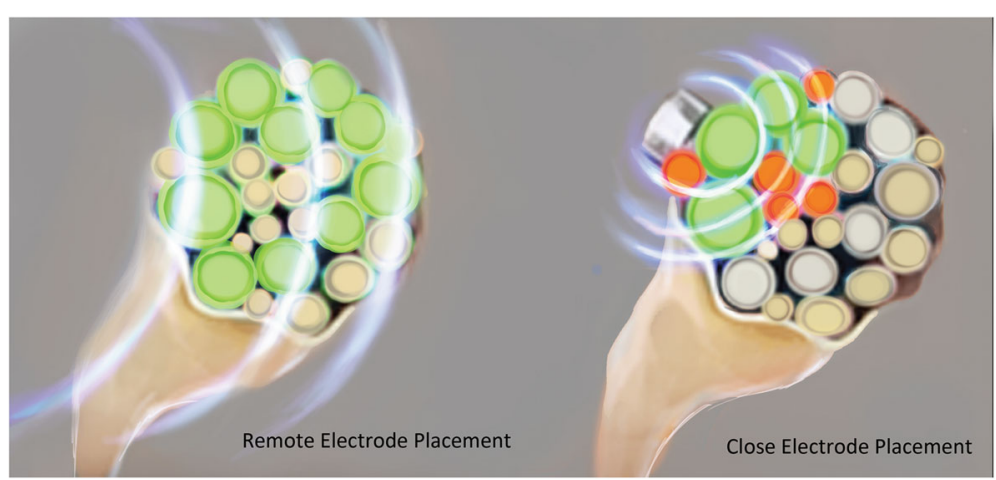

Fig. 6 The therapeutic window and the ability to preferentially activate the targeted large nerve fibers—-without activating non-targeted pain or motor neurons - increases as the distance between the electrode and the nerve increases (illustration used with permission from Brian M. Ifeld, MD, MS)

in situ and occur in less than $8 \%$ of cases $(20$ of 267$)$ when used for the treatment of pain [24, 30, 31, 39-46].

Furthermore, the subjects of this feasibility study underwent treatment $8-58$ days following surgery, and the quality of pain control and impact on supplemental analgesic consumption provided within the first postoperative week remains unknown. Lastly, the subjects of this pilot study underwent stimulation for less than $1 \mathrm{~h}$, while the desirable duration of treatment following total knee arthroplasty would be far longer.

How practical ultrasound-guided percutaneous peripheral nerve stimulation is following total knee arthroplasty as an alternative to opiates and other analgesic techniques will be determined with further research. Ongoing studies are underway with the goal of evaluating safety (e.g., ability to reduce risks of falls relative to existing therapies), efficacy (including during the first postoperative week as well as after the end of stimulation therapy), the potential placebo effect, and the value of the therapy relative to its costs. However, the data provided by the current feasibility study suggest that there is immense potential for making a historic advancement in the treatment of post-surgical pain.

\section{Conclusions}

This prospective feasibility case series suggests that ultrasound-guided percutaneous peripheral nerve stimulation may be applicable to pain following total knee arthroplasty and possibly other orthopedic surgical procedures. If subsequent studies demonstrate a favorable risk-benefit ratio, the modality has the possibility to entirely transform post-surgical pain control as it has been performed administering local anesthetic for over 100 years [47].

\section{Abbreviations}

cm: Centimeters; Fig: Figure; g: Gauge; Hz: Hertz; mA: Milliamps;

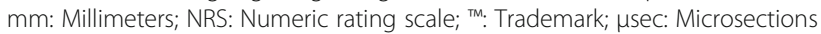

\section{Acknowledgements}

The authors appreciate the invaluable assistance of Jamie Southern (Center for Clinical Research, Winston-Salem, NC) and Jhoanna Aquino (Duke University, Durham, NC), without whom, this study would not have been possible. In addition, the authors thank Haley Chung for her rendering of Figs. 4 and 6.

\section{Funding}

Funding for this project provided by the National Institute on Aging (1R44AG052196-01). In addition, SPR Therapeutics (Cleveland, OH) provided funding and the peripheral nerve electrical leads and stimulators used in this investigation. The content of this article is solely the responsibility of the authors and does not necessarily represent the official views of the funding entities.

\section{Availability of data and materials}

Not applicable (no additional data collected beyond what is included in this report).

\section{Author contributions \\ $\mathrm{BI}$ helped to analyze and interpret the data, authored the original manuscript, supervised the manuscript revisions, and submitted the manuscript for review. CG helped conduct the study and revise the manuscript. SG helped conduct the study and revise the manuscript. MB helped conduct the study and revise the manuscript. DDG helped conduct the study and revise the manuscript. AW helped to design/develop the protocol, conduct the study, and revise the manuscript. JB helped to design/develop the protocol, conduct the study, and revise the manuscript. All authors read and approved the final manuscript.}

\section{Competing interests}

SPR Therapeutics, LLC (Cleveland, OH) provided funding and the peripheral nerve electrical leads and stimulators used in this investigation.

Brian Iffeld: Dr. Iffeld's institution has received funding for his research from SPR Therapeutics (for studies other than the current investigation), Baxter Healthcare, Smiths Medical, Summit Medical, Teleflex Medical, Myoscience, and Pacira Pharmaceuticals. In addition, Dr. Iffeld has also previously acted as a consultant to Pacira Pharmaceuticals.

Christopher Gilmore: Dr. Gilmore's institution has received funding for his research from SPR Therapeutics and Dr. Gilmore has acted as a consultant for SPR Therapeutics.

Stuart Grant: Dr. Grant's institution has received funding for his research from SPR Therapeutics, Cara Therapeutics, and Durrect. Dr. Grant also acts as a consultant to BBraun Medical.

Michael Bolognesi: Dr. Bolognesi's institution has received funding for his research from Zimmer, Biomet, Depuy Synthes, and Exactech. In addition, Dr. Bolognesi is a consultant for Zimmer, Biomet, and Total Joint Orthopedics and receives royalties from Zimmer and Biomet. Lastly, Dr. Bolognesi holds stock or stock options in Total Joint Orthopedics and Amedica.

Daniel Del Gaizo: Dr. Del Gaizo's institution has received funding for his research from Zimmer and Stryker Instruments. In addition, Dr. Del Gaizo has acted as a consultant to SPR Therapeutics. 
Amorn Wongsarnpigoon: Dr. Wongsarnpigoon is an employee of SPR Therapeutics.

Joseph W. Boggs: Dr. Boggs is an employee of SPR Therapeutics and owns equity in the company.

\section{Consent for publication}

Consent to publish was obtained from all participants.

\section{Ethics approval and consent to participate}

This prospective feasibility study was conducted within the ethical guidelines outlined in the Declaration of Helsinki and followed Good Clinical Practice. Approval and oversight were provided by two Institutional Review Boards (Western IRB, Puyallup, WA; and Duke University Health System IRB, Durham, NC). An Investigational Device Exemption was granted for the use of these investigational devices by the US Food and Drug Administration (FDA); and consent to participate was obtained in the form of written, informed consent from all subjects. The protocol was not registered as this was not a randomized, controlled trial.

\section{Author details}

${ }^{1}$ Department of Anesthesiology, University of California San Diego, 200 West Arbor Drive, MC 8770, San Diego, CA 92103-8770, USA. ²Department of Anesthesiology, Wake Forest University Baptist Medical Center, 145 Kimel Park Drive, Ste 330, Winston-Salem, NC 27103, USA. ${ }^{3}$ The Center for Clinical Research, Winston-Salem, NC, USA. ${ }^{4}$ Carolinas Pain Institute, Winston-Salem, NC, USA. ${ }^{5}$ Department of Anesthesiology, Duke University Medical Center, DUMC 3094, Durham, NC 27710, USA. ${ }^{6}$ Department of Orthopedic Surgery, Duke University Medical Center, 200 Trent Dr. \#5216, Durham, NC 27710, USA. ${ }^{7}$ Department of Orthopedic Surgery, University of North Carolina, 3147 Bioinformatics Building, 130 Mason Farm Road, Chapel Hill, NC 27599-7055, USA. ${ }^{8}$ SPR Therapeutics, LLC, 22901 Millcreek Blvd, Suite 110, Cleveland, OH 44122, USA.

Received: 16 June 2016 Accepted: 19 December 2016

Published online: 13 January 2017

\section{References}

1. Kharasch ED, Brunt LM. Perioperative opioids and public health Anesthesiology. 2016;124:960-5.

2. Ilfeld BM, Duke KB, Donohue MC. The association between lower extremity continuous peripheral nerve blocks and patient falls after knee and hip arthroplasty. Anesth Analg. 2010;111:1552-4.

3. Capdevila X, Bringuier S, Borgeat A. Infectious risk of continuous peripheral nerve blocks. Anesthesiology. 2009;110:182-8.

4. Iffeld BM. Continuous peripheral nerve blocks: a review of the published evidence. Anesth Analg. 2011;113:904-25.

5. Gildenberg PL. History of electrical neuromodulation for chronic pain. Pain Med. 2006;7:S7-13.

6. Guan Y. Spinal cord stimulation: neurophysiological and neurochemical mechanisms of action. Curr Pain Headache Rep. 2012;16:217-25.

7. Melzack R, Wall PD. Pain mechanisms: a new theory. Science. 1965;150:971-9.

8. Campbell JN, Taub A. Local analgesia from percutaneous electrical stimulation. A peripheral mechanism. Arch Neurol. 1973;28:347-50.

9. Wall PD, Sweet WH. Temporary abolition of pain in man. Science. 1967;155:108-9.

10. Long DM. Electrical stimulation for relief of pain from chronic nerve injury. J Neurosurg. 1973;39:718-22.

11. Deer TR, Mekhail N, Provenzano D, Pope J, Krames E, Leong M, Levy RM, Abejon D, Buchser E, Burton A, Buvanendran A, Candido K, Caraway D, Cousins M, DeJongste M, Diwan S, Eldabe S, Gatzinsky K, Foreman RD, Hayek S, Kim P, Kinfe T, Kloth D, Kumar K, Rizvi S, Lad SP, Liem L, Linderoth B, Mackey S, McDowell G, McRoberts P, Poree L, Prager J, Raso L, Rauck R, Russo M, Simpson B, Slavin K, Staats P, Stanton-Hicks M, Verrills P, Wellington J, Williams K, North R, Neuromodulation Appropriateness Consensus $C$. The appropriate use of neurostimulation of the spinal cord and peripheral nervous system for the treatment of chronic pain and ischemic diseases: the Neuromodulation Appropriateness Consensus Committee. Neuromodulation. 2014;17:515-50.

12. Deer TR, Mekhail N, Petersen E, Krames E, Staats P, Pope J, Saweris Y, Lad SP, Diwan S, Falowski S, Feler C, Slavin K, Narouze S, Merabet L, Buvanendran A, Fregni F, Wellington J, Levy RM. The appropriate use of neurostimulation: stimulation of the intracranial and extracranial space and head for chronic pain. Neuromodulation. 2014;17:551-70.

13. Hassenbusch SJ, Stanton-Hicks M, Schoppa D, Walsh JG, Covington EC. Long-term results of peripheral nerve stimulation for reflex sympathetic dystrophy. J Neurosurg. 1996;84:415-23.

14. Nashold Jr BS, Goldner JL. Electrical stimulation of peripheral nerves for relief of intractable chronic pain. Med Instrum. 1975;9:224-5.

15. Picaza JA, Cannon BW, Hunter SE, Boyd AS, Guma J, Maurer D. Pain suppression by peripheral nerve stimulation. Part II. Observations with implanted devices. Surg Neurol. 1975;4:115-26.

16. Campbell JN, Long DM. Peripheral nerve stimulation in the treatment of intractable pain. J Neurosurg. 1976;45:692-9.

17. Long DM, Erickson D, Campbell J, North R. Electrical stimulation of the spinal cord and peripheral nerves for pain control. A 10-year experience. Appl Neurophysiol. 1981;44:207-17.

18. Mobbs RJ, Nair S, Blum P. Peripheral nerve stimulation for the treatment of chronic pain. J Clin Neurosci. 2007;14:216-23.

19. Nashold Jr BS, Goldner JL, Mullen JB, Bright DS. Long-term pain control by direct peripheral-nerve stimulation. J Bone Joint Surg Am. 1982;64:1-10.

20. Nashold Jr BS, Mullen JB, Avery R. Peripheral nerve stimulation for pain relief using a multicontact electrode system. Technical note. J Neurosurg. 1979;51:872-3.

21. Picaza JA, Hunter SE, Cannon BW. Pain suppression by peripheral nerve stimulation. Chronic effects of implanted devices. Appl Neurophysiol. 1977; 40:223-34.

22. Hymes AC, Raab DE, Yonehiro EG, Nelson GD, Printy AL. Electrical surface stimulation for control of acute postoperative pain and prevention of ileus. Surg Forum. 1973;24:447-9.

23. VanderArk GD, McGrath KA. Transcutaneous electrical stimulation in treatment of postoperative pain. Am J Surg. 1975;130:338-40.

24. Yu DT, Chae J, Walker ME, Hart RL, Petroski GF. Comparing stimulationinduced pain during percutaneous (intramuscular) and transcutaneous neuromuscular electric stimulation for treating shoulder subluxation in hemiplegia. Arch Phys Med Rehabil. 2001;82:756-60.

25. Yu DT, Chae J, Walker ME, Fang ZP. Percutaneous intramuscular neuromuscular electric stimulation for the treatment of shoulder subluxation and pain in patients with chronic hemiplegia: a pilot study. Arch Phys Med Rehabil. 2001;82:20-5.

26. Monti E. Peripheral nerve stimulation: a percutaneous minimally invasive approach. Neuromodulation. 2004;7:193-6.

27. Huntoon MA, Hoelzer BC, Burgher AH, Hurdle MF, Huntoon EA. Feasibility of ultrasound-guided percutaneous placement of peripheral nerve stimulation electrodes and anchoring during simulated movement: part two, upper extremity. Reg Anesth Pain Med. 2008;33:558-65.

28. Huntoon MA, Huntoon EA, Obray JB, Lamer TJ. Feasibility of ultrasound-guided percutaneous placement of peripheral nerve stimulation electrodes in a cadaver model: part one, lower extremity. Reg Anesth Pain Med. 2008; 33:551-7.

29. Huntoon MA, Burgher AH. Ultrasound-guided permanent implantation of peripheral nerve stimulation (PNS) system for neuropathic pain of the extremities: original cases and outcomes. Pain Med. 2009;10:1369-77.

30. Rauck RL, Kapural L, Cohen SP, North JM, Gilmore CA, Zang RH, Boggs JW. Peripheral nerve stimulation for the treatment of postamputation pain-a case report. Pain Pract. 2012;12:649-55.

31. Rauck RL, Cohen SP, Gilmore CA, North JM, Kapural L, Zang RH, Grill JH, Boggs JW. Treatment of post-amputation pain with peripheral nerve stimulation. Neuromodulation. 2014;17:188-97.

32. Weiner RL. Occipital neurostimulation for treatment of intractable headache syndromes. Acta Neurochir Suppl. 2007;97:129-33.

33. Ilfeld BM, Gabriel RA, Saulino MF, Chae J, Peckham PH, Grant SA, Gilmore CA, Donohue MC, deBock MG, Wongsarnpigoon A, Boggs JW. Infection rate of electrical leads used for percutaneous neuromuscular stimulation of the peripheral nervous system. Pain Practice. [Epub ahead of print].

34. Gorman PH, Mortimer JT. The effect of stimulus parameters on the recruitment characteristics of direct nerve stimulation. IEEE Trans Biomed Eng. 1983;30:407-14.

35. Grill WM, Mortimer JT. Stimulus waveforms for selective neural stimulation. IEEE Trans Biomed Eng. 1995;14:375-85.

36. Jaeger P, Grevstad U, Henningsen MH, Gottschau B, Mathiesen O, Dahl JB. Effect of adductor-canal-blockade on established, severe post-operative pain 
after total knee arthroplasty: a randomised study. Acta Anaesthesiol Scand. 2012;56:1013-9.

37. Jaeger $P$, Koscielniak-Nielsen ZJ, Schroder HM, Mathiesen O, Henningsen MH, Lund J, Jenstrup MT, Dahl JB. Adductor canal block for postoperative pain treatment after revision knee arthroplasty: a blinded, randomized, placebo-controlled study. PLoS One. 2014;9:e111951.

38. Shellock FG. MRI safety and neuromodulation systems, neuromodulation. Edited by Krames ES, Peckham PH, Rezai AR. Cambridge: Elsevier; 2009 p. 243-81.

39. Renzenbrink GJ, IJzerman MJ. Percutaneous neuromuscular electrical stimulation (P-NMES) for treating shoulder pain in chronic hemiplegia. Effects on shoulder pain and quality of life. Clin Rehabil. 2004;18:359-65.

40. Chae J, Wilson RD, Bennett ME, Lechman TE, Stager KW. Single-lead percutaneous peripheral nerve stimulation for the treatment of hemiplegic shoulder pain: a case series. Pain Pract. 2013:13:59-67.

41. Chae J, Yu DT, Walker ME, Kirsteins A, Elovic EP, Flanagan SR, Harvey RL, Zorowitz RD, Frost FS, Grill JH, Fang ZP. Intramuscular electrical stimulation for hemiplegic shoulder pain: a 12-month follow-up of a multiple-center, randomized clinical trial. Am J Phys Med Rehabil. 2005;84:832-42.

42. Wilson RD, Bennett ME, Lechman TE, Stager KW, Chae J. Single-lead percutaneous peripheral nerve stimulation for the treatment of hemiplegic shoulder pain: a case report. Arch Phys Med Rehabil. 2011:92:837-40.

43. Wilson RD, Harris MA, Bennett ME, Chae J. Single-lead percutaneous peripheral nerve stimulation for the treatment of shoulder pain from subacromial impingement syndrome. PM R. 2012;4:624-8.

44. Yu DT, Chae J, Walker ME, Kirsteins A, Elovic EP, Flanagan SR, Harvey RL, Zorowitz RD, Frost FS, Grill JH, Feldstein M, Fang ZP. Intramuscular neuromuscular electric stimulation for poststroke shoulder pain: a multicenter randomized clinical trial. Arch Phys Med Rehabil. 2004;85:695-704.

45. Wilson RD, Gunzler DD, Bennett ME, Chae J. Peripheral nerve stimulation compared with usual care for pain relief of hemiplegic shoulder pain: a randomized controlled trial. Am J Phys Med Rehabil. 2014;93:17-28.

46. Wilson RD, Harris MA, Gunzler DD, Bennett ME, Chae J. Percutaneous peripheral nerve stimulation for chronic pain in subacromial impingement syndrome: a case series. Neuromodulation. 2014:17:771-6. discussion 776.

47. van Zundert A, Helmstadter A, Goerig M, Mortier E. Centennial of intravenous regional anesthesia. Bier's Block (1908-2008). Reg Anesth Pain Med. 2008;33:483-9.

\section{Submit your next manuscript to BioMed Central and we will help you at every step:}

- We accept pre-submission inquiries

- Our selector tool helps you to find the most relevant journal

- We provide round the clock customer support

- Convenient online submission

- Thorough peer review

- Inclusion in PubMed and all major indexing services

- Maximum visibility for your research

Submit your manuscript at www.biomedcentral.com/submit

) Biomed Central 